\title{
The role of injection cues in the production of the morphine preexposure effect in taste aversion learning
}

\author{
Catherine M. Davis \\ American University, Washington, D.C. \\ ISABEL DE BRUGADA \\ Universidad de Granada, Granada, Spain \\ AND \\ Anthony L. Riley \\ American University, Washington, D.C.
}

\begin{abstract}
The attenuation of an LiCl-induced conditioned taste aversion (CTA) by $\mathrm{LiCl}$ preexposure is mediated primarily by associative blocking via injection-related cues. Given that preexposure to morphine attenuates morphine-induced CTAs, it was of interest to determine whether injection cues also mediate this effect. Certain morphine-induced behaviors such as analgesic tolerance are controlled associatively, via injection-related cues. Accordingly, animals in the present experiments were preexposed to morphine (or vehicle) every other day for five total exposures, followed by an extinction phase, in which the subjects were given saline injections (or no treatment) for 8 (Experiment 1) or 16 (Experiment 2) consecutive days. All of the animals then received five CTA trials with morphine (or vehicle). The morphine-preexposed animals in Experiment 1 displayed an attenuation of the morphine CTA that was unaffected by extinction saline injections, suggesting that blocking by injection cues during morphine preexposure does not mediate this effect. All of the morphine-preexposed subjects in Experiment 2 displayed a weakened preexposure effect, an effect inconsistent with a selective extinction of drug-associated stimuli. The attenuating effects of morphine preexposure in aversion learning are most likely controlled by nonassociative mechanisms, like drug tolerance.
\end{abstract}

Animals readily come to avoid solutions that have previously been paired with one of a number of compounds, an avoidance based on the association of the solution with the aversive effects of the drug (for a review, see Freeman \& Riley, 2008; see also Garcia \& Ervin, 1968; Revusky \& Garcia, 1970; Rozin \& Kalat, 1971; for an alternative interpretation, see Grigson, 1997). Such avoidance is rapidly acquired and produced by a wide variety of compounds (e.g., LiCl, emetine, cocaine, morphine, and alcohol; for a review, see Riley \& Tuck, 1985). Interestingly, animals receiving noncontingent exposures to the drug prior to aversion learning typically display an attenuation of the subsequent avoidance (for reviews, see Braveman, 1977; Cappell \& LeBlanc, 1975b; Randich \& LoLordo, 1979; Riley \& Simpson, 2001). This attenuation by previous drug exposures defines the preexposure effect and has been examined with numerous compounds, including $\mathrm{LiCl}$ and a host of abused substances, such as morphine, amphetamine, cocaine, nicotine, and ethanol (Barker \& Johns, 1978; Berman \& Cannon, 1974; Bienkowski, Piasecki, Koros, Stefanski, \& Kostowski, 1998;
Braveman, 1979; Brown, Amit, Smith, \& Rockman, 1979; Cappell \& LeBlanc, 1975a, 1977; Cappell \& Poulos, 1979; Dacanay \& Riley, 1982; Davis \& Riley, 2007; DeBeun, Lohmann, Schneider, \& de Vry, 1996; Ferrari \& Riley, 1994; Goudie, Taylor, \& Atherton, 1975; Riley, Dacanay, \& Mastropaolo, 1984; Riley \& Diamond, 1998; Shoaib \& Stolerman, 1996; Simpson \& Riley, 2005; Ton \& Amit, 1983).

The specific mechanism(s) underlying the preexposure effect in taste aversion learning remains unknown, although numerous researchers have sought to determine how various drugs produce this effect (Aragon, Abitbol, \& Amit, 1986; Bienkowski et al., 1998; Braveman, 1975; Cannon, Berman, Baker, \& Atkinson, 1975; Cappell \& LeBlanc, 1977; Cole, VanTilburg, Burch-Vernon, \& Riccio, 1996; Cunningham \& Linakis, 1980; Dacanay \& Riley, 1982; Ford \& Riley, 1984; Misanin, Hoefel, Riedy, Wilson, \& Hinderliter, 2000). The drug that has received the most attention in this context is $\mathrm{LiCl}$ (Batson, 1983; Batson \& Best, 1979; Braveman, 1978; Cole et al., 1996; de Brugada, González, \& Cándido, 2003; de Brugada, Hall, \& 
Symonds, 2004; Domjan \& Best, 1980; Klein, Mikulka, \& Lucci, 1986; Revusky, Coombes, \& Pohl, 1982; Riley, Jacobs, \& LoLordo, 1976; Rudy, Iwens, \& Best, 1977; Willner, 1978). Interestingly, most researchers assessing the unconditioned stimulus (US) preexposure effect with $\mathrm{LiCl}$ have argued that the attenuation is a function of associative blocking. Specifically, it has been argued that cues present during $\mathrm{LiCl}$ preexposure become associated with LiCl's effects and subsequently block the association between saccharin and LiCl-induced sickness when conditioning is attempted in the presence of those cues. Although blocking seems to account for the attenuating effects of $\mathrm{LiCl}$ preexposure, the specific feature responsible for this effect (e.g., the preexposure environment itself, handling cues, or the injection procedure) has been widely debated (Batson \& Best, 1979; Braveman, 1978; Dacanay \& Riley, 1982; de Brugada et al., 2004; Riley et al., 1976; Rudy et al., 1977; for reviews, see Braveman, 1977; Riley \& Simpson, 2001).

More recently, de Brugada et al. (2003) argued that the attenuation of a LiCl-induced taste aversion by $\mathrm{LiCl}$ preexposure is primarily a consequence of blocking by injection-related cues present throughout preexposure and conditioning (see Batson \& Best, 1979; Braveman, 1979; Dacanay \& Riley, 1982; Willner, 1978). This position was based on the fact that animals receiving $\mathrm{LiCl}$ preexposure and then given a series of saline injections following this preexposure no longer displayed the US preexposure effect; that is, they readily acquired the subsequent saccharin- $\mathrm{LiCl}$ association. According to de Brugada et al. (2003), the saline injections extinguished the association of the injection cues with $\mathrm{LiCl}$, allowing for the subsequent association of the novel taste with LiCl's effects. Under these conditions, the injection cues no longer predicted the effects of $\mathrm{LiCl}$, preventing them from blocking subsequent taste aversion conditioning.

As was noted above, drugs other than $\mathrm{LiCl}$ also produce the preexposure effect; however, it is unknown what role, if any, injection-related cues play in the production of the preexposure effect with these drugs, including drugs of abuse. For example, morphine is one drug of abuse that has been extensively examined in the preexposure design, and preexposure to morphine has been found to consistently attenuate morphine-induced aversions in this preparation (Cappell \& LeBlanc, 1977; Dacanay \& Riley, 1982; Domjan \& Siegel, 1983; Gaiardi et al., 1991; LeBlanc \& Cappell, 1974; Riley et al., 1984; Simpson \& Riley, 2005). Interestingly, varying the environmental cues from preexposure to conditioning does not disrupt the morphine-induced preexposure effect (Dacanay \& Riley, 1982; Stewart \& Eikelboom, 1978), suggesting that this effect is not mediated by environmental cues available to the animal during preexposure. However, it is possible that the same injection-related cues that play a primary role in the production of the $\mathrm{LiCl}$ preexposure effect could be pivotal to the production of the morphine preexposure effect as well. Note that injection-related cues are important in the production of morphine analgesic tolerance, and when these cues are extinguished, tolerance is diminished (Cepeda-Benito \& Tiffany, 1995; Dafters \& Bach, 1985). Indeed, it seems possible that injection cues could play a role in the effects of other morphine-induced behaviors after prior exposure to morphine, such as the attenuating effects of morphine preexposure on aversion learning.

Accordingly, Experiment 1 was designed to test the role of injection cues in the morphine preexposure effect in taste aversion learning. Briefly, animals were administered morphine or vehicle preexposure every other day for 5 days in the home cage, after which half of the animals received vehicle injections (the other half were left undisturbed) in order to extinguish injection-related cues received during the preexposure phase. Following this, the animals received morphine taste aversion conditioning in the home cage.

\section{EXPERIMENT 1}

\section{Method}

\section{Subjects}

The subjects were 67 experimentally naive male Sprague Dawley rats obtained from Harlan Sprague Dawley, Indianapolis. The average weight of the subjects at the initiation of the study was $315 \mathrm{~g} \pm$ $1.8 \mathrm{~g}$.

\section{Apparatus}

The animals were individually housed in hanging wire-mesh cages $(24 \times 19 \times 18 \mathrm{~cm})$ with ad libitum access to food. They were maintained on a 12:12-h light:dark cycle (lights on at $0800 \mathrm{~h}$ ) and at an ambient temperature of $23^{\circ} \mathrm{C}$ for the duration of the experiment. Graduated 50-ml Nalgene tubes were attached to the front of the cages, providing either water or saccharin during the 20 -min fluidaccess period.

\section{Drugs and Solutions}

Morphine sulfate (generously supplied by NIDA) was prepared as a $5-\mathrm{mg} / \mathrm{ml}$ solution in physiological saline (drug vehicle). Saccharin $(0.1 \%$ sodium saccharin; Sigma) was prepared as a $1-\mathrm{g} / 1$ solution in tap water. All doses of morphine are expressed as the salt.

\section{Procedure}

Phase 1: Habituation. After $23 \mathrm{~h}$ of water deprivation, rats were given 20 -min access to water daily, beginning at $1000 \mathrm{~h}$, until they were approaching and drinking from the tube within $2 \mathrm{sec}$ of its presentation. Once drinking was stable, defined as the amount consumed not differing by more than $2 \mathrm{ml}$ for 3 consecutive days for each animal, drug preexposure began.

Phase 2: Preexposure. Water consumption was recorded and averaged over the last 3 days of habituation for all subjects. The animals were ranked on average water consumption and were assigned to a preexposure condition (morphine, Group $\mathrm{M}, n=33$; vehicle, Group $\mathrm{V}, n=34)$. Approximately $51 / 2 \mathrm{~h}$ after their regular 20 -min access to water, the animals were injected subcutaneously (SC) with morphine $(5 \mathrm{mg} / \mathrm{kg})$ or equivolume saline (vehicle) every other day for 10 days (five total morphine or vehicle injections). No injections were given on the intervening days. All preexposure injections were given between $1550 \mathrm{~h}$ and $1650 \mathrm{~h}$. Fluid intake was monitored throughout the preexposure phase.

Phase 3: Extinction. Water consumption for Groups $M$ and V was recorded and averaged over the last 3 days of the preexposure phase. The animals within each group ( $\mathrm{M}$ or $\mathrm{V}$ ) were ranked on average water consumption and assigned to an extinction condition (extinction injections, Group ME, $n=17$, and Group VE, $n=17$; no extinction injections, Group MN, $n=16$, and Group VN, $n=17$ ). 
Approximately $51 / 2 \mathrm{~h}$ after their regular 20-min access to water, the animals in the extinction injections groups (ME and $\mathrm{VE}$ ) received an $\mathrm{SC}$ injection of saline equivolume to the preexposure injections, once a day for 8 consecutive days. The animals in the no extinction injections groups ( $\mathrm{MN}$ and $\mathrm{VN}$ ) were left undisturbed during this time. Injections were given between $1550 \mathrm{~h}$ and $1650 \mathrm{~h}$. Fluid intake was monitored throughout the extinction phase as well.

Phase 4: Conditioning. On the day following the last day of the extinction phase, conditioning began. On Day 1 of this phase, all of the animals were given 20-min access to a novel saccharin solution. After saccharin access, the animals within each group were ranked on saccharin consumption to enable matching of fluid consumption within each group. These procedures yielded eight experimental groups: Group MEM $(n=9)$, Group MNM $(n=8)$, Group VEM $(n=9)$, Group VNM $(n=8)$, Group MEV $(n=8)$, Group MNV $(n=8)$, Group VEV $(n=8)$, and Group VNV $(n=9)$. The first letter denotes the preexposure drug, the second letter denotes the extinction condition, and the third letter denotes the conditioning drug. The subjects were then given SC injections of morphine $(5 \mathrm{mg} / \mathrm{kg})$ or equivolume vehicle immediately following saccharin access. On the following 3 days, the animals received water during their 20-min fluid-access period. This 4-day cycle of a conditioning day followed by 3 water-recovery days constituted one conditioning cycle, and four of these cycles were run.

Phase 5: Aversion test. On the day following the third waterrecovery day of the fourth conditioning cycle, all of the animals were given a final one-bottle aversion test. During the 20-min fluid access period, the animals were given the saccharin solution and consumption was recorded. No injections followed this saccharin exposure.

\section{Results}

No differences in water consumption were found for the various groups during the preexposure and extinction phases of the experiment (data not shown). Mean saccharin consumption on Conditioning Trials $1-4$ was analyzed using a 4 (trial) $\times 2$ (preexposure) $\times 2$ (extinction condition) $\times 2$ (conditioning drug) multifactor ANOVA, with trial as the repeating factor. A significant withinsubjects main effect of trial $[F(3,177)=5.495, p<.05]$ was found, along with significant trial $\times$ preexposure $[F(3,177)=10.333, p<.05]$, trial $\times$ extinction condition $[F(3,177)=3.604, p<.05]$, trial $\times$ conditioning $\operatorname{drug}[F(3,177)=16.382, p<.05]$, and trial $\times$ extinction injections $\times$ conditioning drug $[F(3,177)=3.299, p<$ $.05]$ interactions. The between-subjects main effects of preexposure $[F(1,59)=7.393, p<.05]$, extinction condition $[F(1,59)=4.620, p<.05]$, and conditioning drug $[F(1,59)=49.403, p<.05]$ were significant. No other effects were significant (all $p \mathrm{~s} \geq .135$ ).

For the aversion test, a 2 (preexposure drug) $\times 2$ (extinction condition) $\times 2$ (conditioning drug) univariate ANOVA was performed on saccharin consumption for all of the animals. The between-subjects main effects of preexposure $[F(1,66)=15.718, p<.05]$ and conditioning drug $[F(1,66)=57.859, p<.05]$ were significant. However, the main effect of extinction condition was not significant ( $p=.311)$. The two-way interaction of preexposure and conditioning drug $[F(1,66)=7.260$, $p<.05]$ was significant. Tukey-corrected post hoc tests revealed that, collapsed across extinction condition, the animals preexposed to vehicle and conditioned with morphine consumed less saccharin relative to all other groups, including the animals preexposed to mor- phine and conditioned with morphine (all $p$ s $<.05$; see Figure 1). The two-way interaction of preexposure and extinction condition and the three-way interaction of preexposure drug, extinction condition, and conditioning drug were not significant, suggesting that the extinction manipulation had no effect on the attenuation of the morphine-induced aversion seen in the subjects preexposed to morphine. Interestingly, the extinction $\times$ conditioning drug interaction approached significance $[F(1,66)=3.983, p=.051]$, suggesting that although the extinction manipulation did not affect the preexposure manipulation per se, it did have an effect on conditioning (slightly decreasing saccharin consumption) in groups receiving morphine during conditioning after receiving vehicle injections during extinction.

\section{EXPERIMENT 2}

In Experiment 1, the animals receiving morphine preexposure followed by saline injections in the extinction phase did not display any decrease in saccharin consumption relative to the animals receiving morphine preexposure that remained undisturbed during that time; that is, the extinction manipulation did not alter the morphine preexposure effect. The fact that the extinction injections had no effect on saccharin consumption suggests that the morphine preexposure effect is not mediated by injection cues associated with morphine's effects during the preexposure phase. It could be argued, however, that the number of extinction injections administered in Experiment 1 (one injection per day for 8 days) was not sufficient to disrupt the association of the injection cues with morphine's effects, given that the rats received 5 preexposure injections of morphine. To address this possibility, in Experiment 2, the number of extinction injections was increased (from 8 to 16). If the preexposure effect with morphine is mediated via the association of injection cues with morphine, it would be expected that increasing the number of extinction injections would weaken this association, allowing for an association of saccharin with morphine during aversion conditioning. Nonhandled, morphine-preexposed subjects should still display an attenuated aversion, given that no extinction would be expected in this group. Interestingly, if the preexposure effect is mediated nonassociatively (via tolerance), one would expect that all of the subjects preexposed to morphine would display a weakened preexposure effect, given the dissipation of tolerance over the extinction period (see Cappell \& LeBlanc, 1975a, 1977).

\section{Method}

\section{Subjects and Procedure}

The subjects were 68 experimentally naive male Sprague Dawley rats, with an average weight of $321 \mathrm{~g} \pm 1.7 \mathrm{~g}$. The subjects were maintained and run under conditions identical to those of Experiment 1 . The only exception was that the number of extinction sessions was increased from 8 to 16 . Specifically, approximately $51 / 2 \mathrm{~h}$ after their regular 20-min access to water during the extinction phase, the animals in the extinction injections groups (Group ME, $n=18$, and Group VE, $n=16$ ) received an SC injection of 


\section{Extinction Injections}

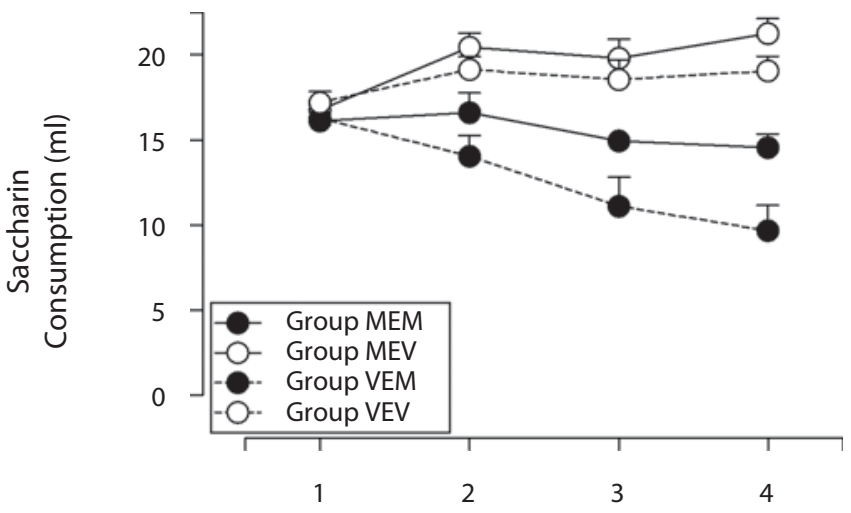

Trial
No Extinction Injections

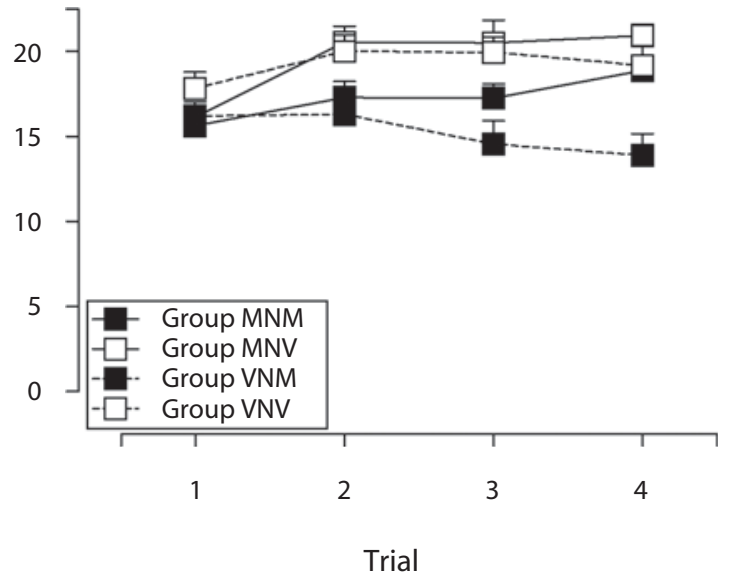

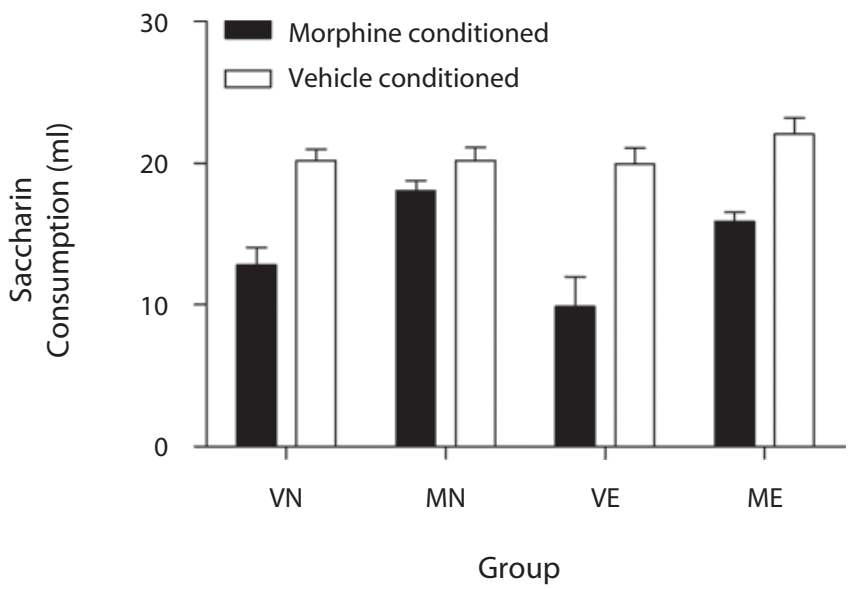

Figure 1. Mean saccharin consumption on Conditioning Trials 1-4 and on the aversion test for all animals conditioned with morphine (black; Groups MEM, VEM, MNM, and VNM) or vehicle (white; Groups MEV, VEV, MNV, and VNV). All animals receiving morphine preexposure and conditioned with morphine, regardless of extinction injections, displayed an attenuated morphine-induced aversion relative to animals that received vehicle during the preexposure period and were conditioned with morphine, regardless of extinction condition. Morphine preexposure attenuated the morphine-induced aversion, and the extinction injections had no influence on this attenuation. Error bars represent $\pm S E M$.

saline, equivolume to the preexposure injections, once a day for 16 consecutive days. The animals in the no extinction injections groups (Group $\mathrm{MN}, n=16$, and Group VN, $n=18$ ) were left undisturbed during this time.

\section{Results}

Similar to that of Experiment 1, water consumption for all of the animals during the preexposure and extinction phases did not differ (data not shown). A 4 (trial) $\times$ 2 (preexposure) $\times 2$ (extinction condition) $\times 2$ (conditioning drug) repeated measures ANOVA was performed on the mean saccharin consumption for Conditioning Trials 1-4. A significant within-subjects main effect of trial $[F(3,180)=14.219, p<.05]$ and significant withinsubjects interactions of trial and preexposure $[F(3,180)=$ $11.215, p<.05]$, trial and conditioning drug $[F(3,180)=$ 53.357, $p<.05]$, and trial, preexposure, and conditioning $\operatorname{drug}[F(3,180)=3.162, p<.05]$ were found. Signifi- cant between-subjects effects of preexposure $[F(1,60)=$ $6.543, p<.05]$ and conditioning drug $[F(1,60)=63.945$, $p<.05]$ were also found. No other effects were significant (all $p \mathrm{~s} \geq .156)$.

A 2 (preexposure drug) $\times 2$ (extinction condition) $\times$ 2 (conditioning drug) univariate ANOVA was performed on saccharin consumption for all of the animals on the aversion test. The between-subjects main effects of preexposure $[F(1,67)=6.367, p<.05]$ and conditioning drug $[F(1,67)=65.285, p<.05]$ were significant. However, the main effect of extinction condition was not significant $(p=.848)$. The two-way interaction of preexposure and conditioning drug $[F(1,67)=1.590, p=.212]$ was not significant, meaning that morphine induced significant aversions in all of the animals, regardless of what they received during the preexposure phase (morphine or vehicle; see Figure 2). The two-way interactions of preexposure and extinction condition and of condition- 


\section{Extinction Injections}

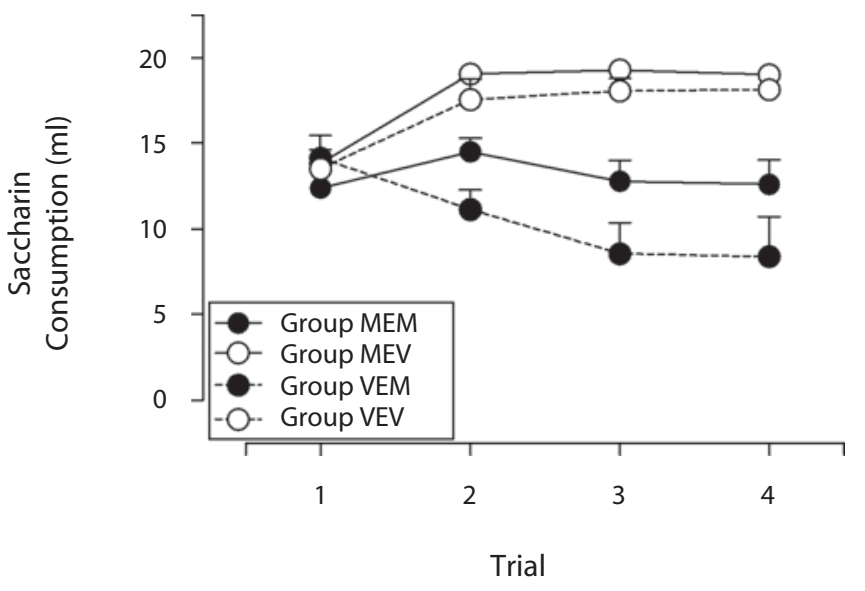

No Extinction Injections

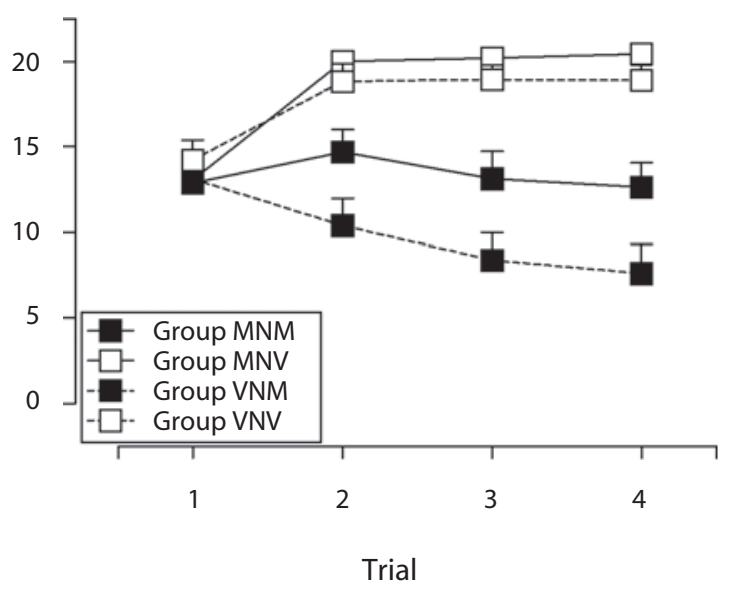

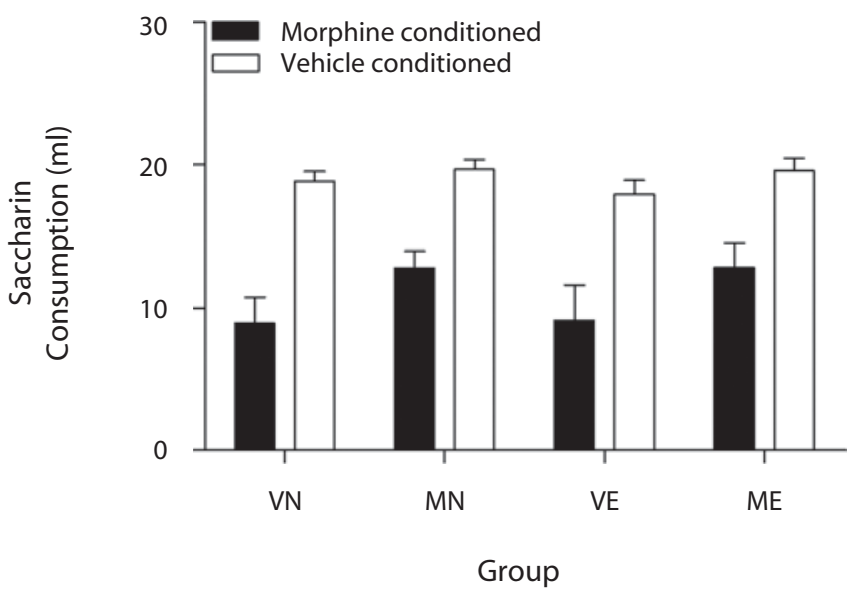

Figure 2. Mean saccharin consumption on Conditioning Trials 1-4 and on the aversion test for all animals conditioned with morphine (black; Groups MEM, VEM, MNM, and VNM) or vehicle (white; Groups MEV, VEV, MNV, and VNV). Morphine conditioned a significant aversion in all subjects, regardless of preexposure drug (morphine, Groups MNM and MEM, or vehicle, Groups VEM and VNM) or extinction condition (extinction injections, Groups MEM and VEM, or no extinction injections, Groups MNM and VNM). Error bars represent $\pm S E M$.

ing drug and extinction condition and the three-way interaction of preexposure drug, extinction condition, and conditioning drug were not significant (all $p \mathrm{~s} \geq .770$ ), suggesting that the extinction manipulation had no effect on consumption in any of the animals.

\section{DISCUSSION}

The present experiments were conducted to determine the role of injection-related cues in the morphine preexposure effect in taste aversion learning (Cappell \& LeBlanc, 1977; Dacanay \& Riley, 1982; Domjan \& Siegel, 1983; Hunt, Spivak, \& Amit, 1985; Miller, Kelly, Neiswander, McCoy, \& Bardo, 1990; Riley et al., 1984; Simpson \& Riley, 2005). In both experiments, subjects received morphine during preexposure, followed by a series of saline injections (to extinguish the association of the injection cues with the effects of morphine) prior to aversion conditioning with morphine. As was reported in Experiment 1, the animals preexposed to morphine displayed an attenuated aversion to the morphine-associated solution relative to conditioned subjects preexposed to vehicle. The degree of attenuation was unaffected by the extinction manipulation, a finding consistent with a nonassociative interpretation of the morphine-induced preexposure effect. However, it was possible that an association had formed between the injection cues and morphine and that the extinction manipulation was insufficient to affect the established association; that is, given that only 8 extinction trials were administered in Experiment 1, it was possible that more extinction injections might be necessary to degrade the morphine-injection cue association. In Experiment 2, we tested the effects of increasing the number of extinction injections (from 8 to 16). As was described, the preexposure effect was generally attenuated in all of the animals on the aversion test. The lack of effect of extinction injections and the degradation of the preexposure effect following the extended time between preexposure and 
conditioning are again consistent with a nonassociative interpretation of the morphine preexposure effect (dissipation of the preexposure effect over time was previously reported by Cappell \& LeBlanc, 1977).

Interestingly, although the extinction manipulation itself did not appear to impact the attenuating effects of morphine preexposure on morphine-induced aversions, it did appear to impact aversion learning in general in Experiment 1 . Specifically, the animals receiving saline injections during extinction displayed slightly stronger aversions to the saccharin solution ( $p=.051)$ than the animals not receiving these injections. This was evident in both the preexposed and the nonpreexposed subjects. The basis for this effect is not known (and was not directly addressed in the present study), but it is possible that exposure to the injection cues themselves (during the extinction phase) may have latently inhibited these cues, weakening their association with morphine during the conditioning phase (see De la Casa \& Lubow, 2000, 2002; Hall \& Channell, 1986; Lubow \& De la Casa, 2005). Consequently, saccharin acquired greater associative strength with morphine, resulting in stronger taste aversions. If this were true, it would suggest that such cues can go into association with morphine and that a greater number of injections would enhance this effect. However, the increased number of extinction injections did not influence conditioning in Experiment 2 (see the Results section). It is unknown why these injection cues did not become associated with morphine during the preexposure phase in Experiment 2 (or, if they did, why they did not appear to be involved in the effects of morphine preexposure). This lack of an effect makes it difficult to conclude that latently inhibited injected cues are the cause of the slightly stronger saccharin-morphine association in animals receiving these extinction injections (see Experiment 1).

These data (relative to those reported with $\mathrm{LiCl}$ ) suggest that the basis for the US preexposure effect in taste aversion learning is drug dependent (at least for morphine and $\mathrm{LiCl}$ ). Because the basis for aversion learning in general (or for any specific drug in particular) is unknown, it is difficult to speculate on exactly what characteristic of the drug is important in this respect. Recent work addressing the basis for associative and nonassociative tolerance of morphine-induced analgesia may provide some insight into the effects reported with morphine and $\mathrm{LiCl}$ in the US preexposure effect in taste aversion learning. Specifically, it has been argued that the likelihood of demonstrating associative or nonassociative tolerance in morphine-induced analgesia may be a function of the onset of drug action (Greeley \& Ryan, 1995; Kim, Siegel, \& Patenall, 1999; Siegel, 2008; Siegel, Baptista, Kim, McDonald, \& WeiseKelly, 2000). If animals are administered morphine via an intraperitoneal injection, there is a rapid onset of drug action. Any contextual stimulus paired with this effect comes to control morphine analgesia; that is, tolerance to morphine is associative in this scenario. If animals are administered morphine via an SC injection, there is a delayed and slow onset of drug action. The initial morphineinduced effects are perceived and precede the maximal effects of the drug. These initial drug effects actually mask or overshadow any contextual stimuli that are present. In this scenario, the contextual stimuli have no control over morphine tolerance and any waning of morphine analgesia (i.e., tolerance) is nonassociative in nature.

Although these arguments were developed to account for changes in the analgesic responses to morphine (Dafters \& Bach, 1985; Grisel, Wiertelak, Watkins, \& Maier, 1994; Kim et al., 1999; Walter \& Riccio, 1983), they may apply to the present results as well. Specifically, morphine was administered subcutaneously in the present studies and is assumed to have a gradual, slow onset of effect, which would overshadow the drug injection cues, subsequently producing the preexposure effect via a pharmacological mechanism (i.e., see Kim et al., 1999; Siegel et al., 2000). If this is the case, degrading the association of the injection cues with morphine's effects by administering extinction injections would not be expected to alter the preexposure effect. The associative control of the $\mathrm{LiCl}$ preexposure effect could be a result of how quickly the full effects of the drug are experienced after injection, allowing for control by contextual cues paired with LiCl's effects. Indeed, de Brugada et al. (2003; de Brugada, Gonzáles, Gil, \& Hall, 2005) administered LiCl intraperitoneally, a route of administration that would be associated with a faster onset of the full effects of a drug, relative to that of subcutaneous administration. This quicker onset could lead to the reported associative control of the $\mathrm{LiCl}$ preexposure effect by the injection-related cues.

On the basis of this logic, it might be predicted that under different parametric conditions, the mechanism underlying the US preexposure effect for morphine (and for $\mathrm{LiCl}$ ) might be different. For example, if during preexposure, morphine was administered intraperitoneally, intravenously, or with an injection over a shorter duration of time, the resulting attenuation might be more associative in nature. Although such parameters may impact the likelihood of tolerance in other behavioral preparations, it is unclear to what extent the basis of the US preexposure effect in aversion learning would be affected. For instance, Domjan and Siegel (1983) reported that parametrically identical preexposure regimens produced associative control of morphine analgesic tolerance but nonassociative control of the morphine preexposure effect on aversion learning. What remains to be determined is why the underlying mechanisms responsible for tolerance to morphine's analgesic effects differ from those responsible for the attenuation of morphine's aversive effects after prior exposure. Nonetheless, it remains to be determined whether other procedural variations such as the number of preexposures and conditioning trials (as well as other parameters) impact the mechanism(s) mediating this effect.

The fact that the US preexposure effect in taste aversion learning is drug dependent encourages investigations into the specific nature of aversion learning and how such an effect is impacted by drug history. Furthermore, that under different behavioral preparations, associative and nonassociative mechanisms can control morphine- and LiCl-induced behaviors encourages investigations into 
how the specific characteristics of each drug interact with specific behavioral preparations to ultimately impact the mechanism(s) mediating these different behaviors and to produce drug-dependent effects.

\section{AUTHOR NOTE}

The authors thank Alexandra DeCicco for her technical assistance. This work was supported by a grant from the Mellon Foundation to A.L.R. and by Grants BSO2003-01327 (partially funded by FEDER) and HUM02763 awarded to I.d.B. Reprint requests and correspondence concerning this article should be addressed to C. M. Davis, Johns Hopkins University School of Medicine, BBRC Bayview-Suite 3020, 5510 Nathan Shock Dr., Baltimore, MD 21224 (e-mail: cdavis91@jhmi.edu).

\section{REFERENCES}

Aragon, C. M. G., Авitbol, M., \& Amit, Z. (1986). Acetaldehyde may mediate reinforcement and aversion produced by ethanol. Neuropharmacology, 25, 79-83.

BARKER, L. M., \& Johns, T. (1978). Effect of ethanol preexposure on ethanol-induced conditioned taste aversion. Journal of Studies on Alcohol, 39, 39-46.

BAtson, J. D. (1983). Effects of repeated lithium injections on temperature, activity, and flavor conditioning in rats. Animal Learning \& Behavior, 11, 199-204.

BAtson, J. D., \& Best, P. J. (1979). Drug-preexposure effects in flavoraversion learning: Associative interference by conditioned environmental stimuli. Journal of Experimental Psychology: Animal Behavior Processes, 5, 273-283.

Berman, R. F., \& Cannon, D. S. (1974). The effect of prior ethanol experience on ethanol-induced saccharin aversions. Physiology \& Behavior, 12, 1041-1044.

Bienkowski, P., Piasecki, J., Koros, E., Stefanski, R., \& KosTOWSKI, W. (1998). Studies on the role of nicotinic acetylcholine receptors in the discriminative and aversive stimulus properties of ethanol in the rat. European Neuropsychopharmacology, 8, 79-87.

Braveman, N. S. (1975). Formation of taste aversions in rats following prior exposure to sickness. Learning \& Motivation, 6, 512-534.

BRAVEMAN, N. S. (1977). What studies on pre-exposure to pharmacological agents tell us about the nature of the aversion-inducing treatment. In L. M. Barker, M. R. Best, \& M. Domjan (Eds.), Learning mechanisms in food selection (pp. 511-530). Waco, TX: Baylor University Press.

BRAVEMAN, N. S. (1978). The role of handling cues in the treatment preexposure effect in taste aversion learning. Bulletin of the Psychonomic Society, 12, 74-76.

Braveman, N. S. (1979). The role of blocking and compensatory conditioning in the treatment preexposure effect. Psychopharmacology, 61, 177-189.

Brown, Z. W., Amit, Z., Smith, B., \& Rockman, G. (1979). Disruption of taste aversion learning by pretreatment with diazepam and morphine. Pharmacology Biochemistry \& Behavior, 10, 17-20.

Cannon, D. S., Berman, R. F., Baker, T. B., \& Atrinson, C. A. (1975). Effect of preconditioning unconditioned stimulus experience on learned taste aversions. Journal of Experimental Psychology: Animal Behavior Processes, 1, 270-284.

Cappell, H. D., \& LeBlanc, A. E. (1975a). Conditioned aversion by amphetamine: Rates of acquisition and loss of the attenuating effects of prior exposure. Psychopharmacologia, 43, 157-162.

Cappell, H. D., \& LeBlanc, A. E. (1975b). Conditioned aversion by psychoactive drugs: Does it have significance for an understanding of drug dependence? Addictive Behaviors, 1, 55-64.

Cappell, H. D., \& LeBlanc, A. E. (1977). Parametric investigations of the effects of prior exposure to amphetamine and morphine on conditioned gustatory aversion. Psychopharmacology, 51, 265-271.

Cappell, H. D., \& Poulos, C. X. (1979). Associative factors in drug pretreatment effects on gustatory conditioning: Cross-drug effects. Psychopharmacology, 64, 209-213.

Cepeda-Benito, A., \& Tiffany, S. T. (1995). Role of drug-administration cues in the associative control of morphine tolerance in the rat. Psychopharmacology, 122, 312-316.
Cole, K. C., VanTilburg, D., Burch-Vernon, A., \& Riccio, D. C. (1996). The importance of context in the US preexposure effect in CTA: Novel versus latently inhibited contextual stimuli. Learning \& Motivation, 27, 362-374.

Cunningham, C. L., \& Linakis, J. G. (1980). Paradoxical aversive conditioning with ethanol. Pharmacology Biochemistry \& Behavior, 12, 337-341.

DaCAnay, R. J., \& Riley, A. L. (1982). The UCS preexposure effect in taste aversion learning: Tolerance and blocking are drug specific. Animal Learning \& Behavior, 10, 91-96.

DAFTERS, R., \& BACH, L. (1985). Absence of environment-specificity in morphine tolerance acquired in non-distinctive environments: Habituation or stimulus overshadowing? Psychopharmacology, 87, 101-106.

Davis, C. M., \& RiLEY, A. L. (2007). The effects of cocaine preexposure on cocaine-induced taste aversion learning in Fischer and Lewis rat strains. Pharmacology Biochemistry \& Behavior, 87, 198-202.

DeBeun, R., Lohmann, A., Schneider, R., \& DE Vry, J. (1996). Ethanol intake-reducing effects of ipsapirone in rats are not due to simple stimulus substitution. Pharmacology Biochemistry \& Behavior, 53, 891-898.

de Brugada, I., González, F., \& Cándido, A. (2003). The role of injection cues in the associative control of the US pre-exposure effect in flavour aversion learning. Quarterly Journal of Experimental Psychology, 56B, 241-252.

de Brugada, I., González, F., Gil, M., \& Hall, G. (2005). The role of habituation of the response to $\mathrm{LiCl}$ in the US-preexposure effect. Learning \& Behavior, 33, 363-370.

DE Brugada, I., Hall, G., \& Symonds, M. (2004). The US-preexposure effect in lithium-induced flavor-aversion conditioning is a consequence of blocking by injection cues. Journal of Experimental Psychology: Animal Behavior Processes, 30, 58-66.

De la CASA, L. G., \& Lubow, R. E. (2000). Super-latent inhibition with delayed conditioned taste aversion testing. Animal Learning \& Behavior, 28, 389-399.

De la CAsa, L. G., \& Lubow, R. E. (2002). An empirical analysis of the super-latent inhibition effect. Animal Learning \& Behavior, 30, 112-120.

Domuan, M., \& Best, M. R. (1980). Interference with ingestional aversion learning produced by preexposure to the unconditioned stimulus: Associative and nonassociative aspects. Learning \& Motivation, 11, 522-537.

Domjan, M., \& Siegel, S. (1983). Attenuation of the aversive and analgesic effects of morphine by repeated administration: Different mechanisms. Biological Psychology, 11, 155-158.

Ferrari, C. M., \& Riley, A. L. (1994). Effect of prenatal cocaine on the acquisition of cocaine-induced taste aversions. Neurotoxicology \& Teratology, 16, 17-23.

Ford, K. A., \& RiLEy, A. L. (1984). The effects of $\mathrm{LiCl}$ preexposure on amphetamine-induced taste aversions: An assessment of blocking. Pharmacology Biochemistry \& Behavior, 20, 643-645.

Freeman, K. B., \& Riley, A. L. (2008). The origins of conditioned taste aversion learning: An historical analysis. In S. Reilly \& T. D. Schachtman (Eds.), Conditioned taste aversions: Neural and behavioral processes (pp. 9-36). New York: Oxford University Press.

Gaiardi, M., Bartoletti, M., Bacchi, A., Gubellini, C., Costa, M., \& BABBINI, M. (1991). Role of repeated exposure to morphine in determining its affective properties: Place and taste conditioning studies in rats. Psychopharmacology, 103, 183-186.

Garcia, J., \& ERvin, F. R. (1968). Gustatory-visceral and telereceptorcutaneous conditioning: Adaptation to internal and external milieus. Communications in Behavioral Biology, A1, 389-415.

Goudie, A. J., Taylor, M., \& Atherton, H. (1975). Effects of prior drug experience on the establishment of taste aversions in rats. Pharmacology Biochemistry \& Behavior, 3, 947-952.

GreEley, J., \& RYAN, C. (1995). The role of interoceptive cues for drug delivery in conditioning models of drug dependence. In D. C. Drummond, S. T. Tiffany, S. Glautier, \& B. Remington (Eds.), Addictive behaviour: Cue exposure therapy and practice (pp. 121-136). Chichester, U.K.: Wiley.

Grigson, P. S. (1997). Conditioned taste aversions and drugs of abuse: A reinterpretation. Behavioral Neuroscience, 111, 129-136.

Grisel, J. E., Wiertelak, E. P., Watkins, L. R., \& Maier, S. F. (1994). 
Route of morphine administration modulates conditioned analgesic tolerance and hyperalgesia. Pharmacology Biochemistry \& Behavior, 49, 1029-1035.

Hall, G., \& Channell, S. (1986). Context specificity of latent inhibition in taste aversion learning. Quarterly Journal of Experimental Psychology, 38B, 121-139.

Hunt, T., SpIVAK, K., \& Amit, Z. (1985). Aversive stimulus properties of morphine: Evaluation using the drug preexposure conditioned taste aversion paradigm. Behavioral \& Neural Biology, 44, 60-73.

Kim, J. A., Siegel, S., \& Patenall, V. R. A. (1999). Drug onset-cues as signals: Intra-administration associations and tolerance. Journal of Experimental Psychology: Animal Behavior Processes, 25, 491-504.

Klein, S. B., MikulKa, P. J., \& LuCCI, K. (1986). Influence of lithium chloride intensity on unconditioned stimulus-alone interference in a flavor aversion paradigm. Learning \& Motivation, 17, 76-90.

LeBlanc, A. E., \& CAPPell, H. D. (1974). Attenuation of punishing effects of morphine and amphetamine by chronic prior treatment. Journal of Comparative \& Physiological Psychology, 87, 691-698.

Lubow, R. E., \& De La CASA, L. G. (2005). There is a time and a place for everything: Bidirectional modulations of latent inhibition by timeinduced context differentiation. Psychonomic Bulletin \& Review, 12, 806-821.

Miller, J. S., Kelly, K. S., Neiswander, J. L., McCoy, D. F., \& BARDO, M. T. (1990). Conditioning of morphine-induced taste aversion and analgesia. Psychopharmacology, 101, 472-480.

Misanin, J. R., Hoefel, T. D., Riedy, C. A., Wilson, H. A., \& HinDERLiter, C. F. (2000). Multiple remote-US preexposures and the blocking effect produced by a proximal-US. Physiology \& Behavior, 71, 199-202.

Randich, A., \& LoLordo, V. M. (1979). Associative and nonassociative theories of the UCS preexposure phenomenon: Implications for Pavlovian conditioning. Psychological Bulletin, 86, 523-548.

Revusky, S., Coombes, S., \& Pohl, R. W. (1982). US preexposure: Effects on flavor aversions produced by pairing a poisoned partner with ingestion. Animal Learning \& Behavior, 10, 83-90.

REvUSKY, S., \& GARCIA, J. (1970). Learned associations over long delays. In G. H. Bower \& J. T. Spence (Eds.), The psychology of learning and motivation: Advances in research and theory (Vol. 4, pp. 1-83). New York: Academic Press.

Riley, A. L., Dacanay, R. J., \& Mastropaolo, J. P. (1984). The effect of morphine preexposure on the acquisition of morphine-induced taste aversions: A nonassociative effect. Animal Learning \& Behavior, 12, 157-162.

RiLey, A. L., \& Diamond, H. F. (1998). The effects of cocaine preexposure on the acquisition of cocaine-induced taste aversions. Pharmacology Biochemistry \& Behavior, 60, 739-745.
Riley, A. L., Jacobs, W. J., \& LoLordo, V. M. (1976). Drug exposure and the acquisition and retention of a conditioned taste aversion. Journal of Comparative \& Physiological Psychology, 90, 799-807.

Riley, A. L., \& Simpson, G. R. (2001). The attenuating effects of drug preexposure on taste aversion conditioning: Generality, experimental parameters, underlying mechanisms, and implications for drug use and abuse. In R. R. Mowrer \& S. B. Klein (Eds.), Handbook of contemporary learning theories (pp. 505-559). Mahwah, NJ: Erlbaum.

RiLey, A. L., \& TucK, D. L. (1985). Conditioned taste aversions: A behavioral index of toxicity. In N. S. Braveman \& P. Bronstein (Eds.), Experimental assessments and clinical applications of conditioned food aversions (Annals of the New York Academy of Sciences, Vol. 443, pp. 272-292). New York: New York Academy of Sciences.

Rozin, P., \& Kalat, J. W. (1971). Specific hungers and poison avoidance as adaptive specializations of learning. Psychological Review, 78, 459-486.

Rudy, J. W., Iwens, J., \& Best, P. J. (1977). Pairing novel exteroceptive cues and illness reduces illness-induced taste aversions. Journal of Experimental Psychology: Animal Behavior Processes, 3, 14-25.

Shoaib, M., \& Stolerman, I. P. (1996). The NMDA antagonist dizocilpine (MK801) attenuates tolerance to nicotine in rats. Journal of Psychopharmacology, 10, 214-218.

Siegel, S. (2008). Learning and the wisdom of the body. Learning \& Behavior, 36, 242-252.

Siegel, S., Baptista, M. A. S., Kim, J. A., McDonald, R. V., \& WeiseKelLy, L. (2000). Pavlovian psychopharmacology: The associative basis of tolerance. Experimental \& Clinical Psychopharmacology, 8, 276-293.

Simpson, G. R., \& Riley, A. L. (2005). Morphine preexposure facilitates morphine place preference and attenuates morphine taste aversion. Pharmacology Biochemistry \& Behavior, 80, 471-479.

Stewart, J., \& Eikelboom, R. (1978). Pre-exposure to morphine and the attenuation of conditioned taste aversions in rats. Pharmacology Biochemistry \& Behavior, 9, 639-645.

Ton, J. M. N. C., \& AMiт, Z. (1983). Symmetrical effect of pre-exposure between alcohol and morphine on conditioned taste aversion. Life Sciences, 33, 665-670.

Walter, T. A., \& Riccio, D. C. (1983). Overshadowing effects in stimulus control of morphine analgesic tolerance. Behavioral Neuroscience, 97, 658-662

WiLLNER, J. A. (1978). Blocking of a taste aversion by prior pairings of exteroceptive stimuli with illness. Learning \& Motivation, 9, 125-140.

(Manuscript received May 27, 2009; revision accepted for publication October 8, 2009.) 